\title{
Current Status of Ectoparasites in Sheep and Management Practices against the Problem in Ectoparasites Controlled and Uncontrolled Areas of Arsi Zone in Oromia Region, Ethiopia
}

\author{
Hailegebriel Bedada, Getachew Terefe and Yacob Hailu Tolossa* \\ College of Veterinary Medicine and Agriculture, Addis Ababa University, Debre Zeit-34, Ethiopia
}

\begin{abstract}
A cross sectional study was conducted to determine the prevalence of ectoparasites of sheep in ectoparasites controlled and uncontrolled areas, assess major risk factors and evaluate effects of ectoparasites on livelihood of farmer in ectoparasites controlled and uncontrolled areas of Arsi zone. A total of 969 sheep (646 sheep from controlled and 323 sheep from uncontrolled areas) were examined for ectoparasites. From controlled $371(57.43 \%)$ and from uncontrolled area $285(88.24 \%)$ were found to be infested with ectoparasites. The ectoparasites identified in controlled area were B. ovis $48.9 \%$, Linognathus spp $0.93 \%$, sheep keds $7.4 \%, 2.32 \%$ B. decoloratus, $1.46 \%$ A. variegatum, $1.08 \%$ A. gemma, $4.59 \% R$. evertsi evertsi, and $0.31 \%$ mixed ticks infestation and $12.5 \%$ mixed infestation with various ectoparasites. Similarly from uncontrolled area identified $B$. ovis $81.4 \%$, Linognathus spp $0.9 \%, 1.79 \%$ B. decoloratus, $2.62 \%$ A. variegatum, $9.29 \%$ R. evertsi evertsi, $4.3 \%$ mixed ticks infestation and $32.2 \%$ mixed infestation. The risk of ectoparasites infestation of sheep in uncontrolled area was 5.644 times higher than in controlled $(\mathrm{OR}=5.644)$. Significantly higher prevalence of ectoparasites in the uncontrolled area than controlled was recorded. The risk of lice, keds and tick infestations in uncontrolled area was 7.061, 3.836 and 2.074 times higher than controlled areas respectively. Poor animal management and weak animal health services were believed to have attributed for widespread distribution of ectoparasites. The effectiveness of ectoparasites control in selected zones of Oromiya region is also under question the. The growing threat of ectoparasites to sheep population in the study areas requires well-coordinated control intervention.
\end{abstract}

Keywords: Controlled/uncontrolled; Arsi zone; Ectoparasites; Sheep; Oromiya

\section{Introduction}

Small ruminants represent the most important part of the Ethiopian livestock system; about 24.2 million sheep are estimated to be found in the country [1]. In Ethiopia sheep is reared in all agro climatic zones. The highland area comprises $70 \%$ of the sheep, while the lowland pastoral and agro pastoral area have $30 \%$ of the sheep population [2]. However, the current level of contributions of sheep in Ethiopia is below the expected potential. Among major constraints hindering the productivity of sheep in the country are diseases, among which sheep skin diseases caused by ectoparasites accounts a wide range of health problems that confront the productivity. Ectoparasites are very common and widely distributed in all agro-ecological zones in Ethiopia [3].

Skin diseases caused by lice, keds, ticks, and mange mites; are among the major diseases of sheep causing serious economic loss to small holder farmer, the tanning industry and the country as a whole. Skin diseases cause mortality, decreased production and reproduction; in addition to these, currently skin diseases affecting the tanning industry very seriously causing enormous down grading and rejection of skins and hides [4,5]. It is reported that $35 \%$ of sheep skin rejections in Ethiopia are attributed to ectoparasites [6]. All these established facts imply that ectoparasites pose serious economic losses to the farmer, the tanning industry and the country as a whole [7].

The control program against ectoparasites and skin diseases have been designed by the Ministry of Agriculture and Rural Development of Ethiopia in 2005 and launched in Tigray, Amhara and Afar regions. In Oromia regional state this activity started in 2010 and still ongoing. Despite such national and regional efforts and emphasis given to the control programs against ectoparasites, some reports from north-west Amhara region indicate the problem seems to be still alarming $[3,8]$.
According to Yacob Hailu Tolossa, Asnake Fekadu et al.[3,9] in many part of the Ethiopia, skin diseases due to ectoparasite have prevented many farmers from keeping sheep and becoming serious threat to sheep production. Despite the large population of sheep in Arsi zone of Oromiya region, ectoparasites are still among serious problems in the area [10]. Even though the Oromiya regional state has started control program against ectoparasites in some selected districts of east and west Arsi zone, the impact of this control program on the status of ectoparasitism was not yet studied. The objectives of this study were therefore (i) To determine the prevalence of major ectoparasites of sheep in selected districts of ectoparasite controlled and uncontrolled areas of Arsi zone (ii) Identify and assess the major risk factors associated with the problem (iii) to evaluate effect of ectoparasites on livelihood of the farmers.

\section{Material and Methods}

\section{Study area and population}

Arsi Zone is found in the central part of the Oromiya Regional State. This zone lies between $6045^{\prime} \mathrm{N}$ to $8058^{\prime} \mathrm{N}$ and $38032^{\prime} \mathrm{E}$ to 400

*Corresponding author: Yacob Hailu Tolossa, College of Veterinary Medicine and Agriculture, Addis Ababa University, Debre Zeit-34, Ethiopia, Tel: 0251-911 476006; Fax: 0251114-339933; E-mail: yamilaya2008@gmail.com

Received June 10, 2015; Accepted June 29, 2015; Published July 01, 2015

Citation: Bedada H, Terefe G, Tolossa YH (2015) Current Status of Ectoparasites in Sheep and Management Practices against the Problem in Ectoparasites Controlled and Uncontrolled Areas of Arsi Zone in Oromia Region, Ethiopia. J Veterinar Sci Technol S10: 002. doi:10.4172/2157-7579.S10-002

Copyright: $\odot 2015$ Bedada $\mathrm{H}$, et al. This is an open-access article distributed unde the terms of the Creative Commons Attribution License, which permits unrestricted use, distribution, and reproduction in any medium, provided the original author and source are credited. 
Citation: Bedada H, Terefe G, Tolossa YH (2015) Current Status of Ectoparasites in Sheep and Management Practices against the Problem in Ectoparasites Controlled and Uncontrolled Areas of Arsi Zone in Oromia Region, Ethiopia. J Veterinar Sci Technol S10: 002. doi:10.4172/21577579.S10-002

Page 2 of 7

$50^{\prime} \mathrm{E}$. The mean annual temperature of the Zone is $20-25^{\circ} \mathrm{C}$ in the low land and $10-15^{\circ} \mathrm{C}$ in the central high land with the mean annual rainfall $633.7 \mathrm{~mm}$ to $1059.3 \mathrm{~mm}[1]$

This study was conducted from October 2013 to May 2014. Study animals were indigenous sheep from three districts (Tiyo, Diksis and Guna) of Arsi Zone which are found 179, 199 and $230 \mathrm{~km}$ away from Addis Ababa, respectively. According to CSA [1] Arsi zone has a total population of sheep $1,207,182$, and goats 653,327 .

\section{Sampling method and sample size determination}

This study involved three districts, peasant associations (PAs) and sheep as a sampling unit. The districts were selected purposively based on their representation of ectoparasite controlled and uncontrolled; five PAs from each district having the corresponding control status were also be selected randomly. Sheep found in selected PAs were selected randomly from animals grazing in communal pastures.

The required sample size was determined as described by Thrusfield [11]. The expected prevalence of ectoparasite was taken from previous work of Hailu [10] in the area before initiation of control program was $70 \%$ and by setting $95 \%$ confidence level and 5\% desired level of precision. Based on the above formula and the livestock population of each study agro-ecology, a total of 969 sheep were examined for ectoparasites. Hence, 646 sheep where sampled from the controlled districts (Diksis and Tiyo) and 323 sheep were sampled from uncontrolled district (Guna).

\section{Study design}

A cross-sectional study was employed and animals were examined for presence of ectoparasites and skin lesions and after proper restraining and specimens were collected from ectoparasites positive animals.

\section{Clinical examinations}

969 sheep randomly selected from one uncontrolled district and two controlled districts were clinically examined for presences of ectoparasites skin and gross lesions. The sex, age and body condition of each sheep was recorded. The animals were categorized into two age groups, as young (up to one year) and adult (older than one year), as described by Gatenby [12]. Age was determined as indicated by owners and estimated by dentition. Body condition scores were determined by modifying the system of Gatenby [12] for sheep as either poor or good. A poor body condition score was given for sheep which were extremely thin, having prominent spinous and transverse processes into which a finger could be easily pushed and had less depth of loin muscle. A good body condition score was given for sheep when the spinous and transverse processes were smooth, rounded and well covered and with full loin muscle.

Clinical examination of each sheep was performed by multiple fleece partings in the direction opposite to that in which hair or wool normally rests, followed by physical inspection of the skin. The skin was palpated across all parts of the animal for the presence of parasites, and gross lesions suggestive of a clinical form of parasitic infestations. Animals found infested were considered positive.

\section{Ectoparasites collection and identification}

Sheep keds, ticks, lice and fleas were collected manually from their sites of attachment. The ticks were removed from the host skins whilst retaining their mouth parts for identification using forceps. Coat brushing techniques were used for collection of lice. They were placed in labeled universal bottles containing 70\% ethanol and identified under a stereoscopic microscope according to the descriptions of Walker [13,14].

\section{Questionnaire survey}

A structured questionnaire was introduced to obtain general information on livestock ownership pattern, importance of keeping sheep, awareness of ectoparasites that affect sheep and their effect on sheep production and market value of the skin and the effect of ectoparasite control program in the area. For the sake of convenience of data and time management a total of 60 individuals who owns sheep were interviewed. For this purpose a total of 20 sheep owners were selected from each district (20 individuals from uncontrolled area and 40 individuals from controlled area). In addition structured questionnaire format was introduced to attain general information on the preconditions set by skin collectors to purchase skin, the cost of ectoparasite infested skin with respect to healthy one, the way of storing collected skin and what was the tannery looking while receiving the collected skin. Nine (9) skin collectors, three from each district were included in the study.

\section{Data analysis}

Raw data was carefully recorded and stored in Microsoft Excel database system used for data management. Statistical software package called SPSS for windows version 17.0 was used for data analysis. Descriptive statistics, percentages and $95 \%$ confidence intervals were used to summarize the proportion of infested and non-infested animals. The effects of different environmental and host risk factors were analyzed by regression and $\chi 2$ test. Statistical significance was set at $\mathrm{p} \leq 0.05$.

\section{Results}

\section{Questionnaire survey result}

Response on livestock ownership pattern indicates that in both ectoparasites controlled and uncontrolled areas, sheep is the major species of animal kept by farmers for various reasons. The major reasons for keeping sheep were 53/60 (88.33\%) for income generation and insurance as priority number one $36 / 40(90 \%)$ in controlled area and $17 / 20(85 \%)$ in uncontrolled area, priority number two were meat for home consumption 49/60 (81.67\%); 34/40 (85\%) in controlled area and $15 / 20(75 \%)$ in uncontrolled area and 53/60 (88.33\%) 36/40 (90\%) in controlled area and $17 / 20(85 \%)$ in uncontrolled area were kept sheep for skin as priority number three. In the controlled area $80 \%$ of the respondents were manage sheep by mixing with the other species of animals and only $20 \%$ of the respondents were manage sheep by separating from the other species of animals. While in uncontrolled area sheep management were $30 \%$ and $70 \%$ separately and by mixing with the other species of animals respectively.

From the total 60 sheep owners interviewed, 28/40 (70\%) and 14/20 $(60 \%)$ respondents from controlled and uncontrolled area respectively knew one or more skin diseases affect sheep. The main skin diseases mentioned by respondents were keds and lice in both ectoparasite controlled and uncontrolled districts. According to the respondents $33 / 40(82.5 \%)$ and $7 / 40(17.5 \%)$ mange affect adult sheep and all age group in controlled area respectively and in uncontrolled area 17/20 $(85 \%)$ and $3 / 20(15 \%)$ mange affect adult and all age group respectively. In controlled area sheep keds 26/40 (65\%), 4/40 (10\%) and 10/40 (25\%) affect adult, young and all age group respectively; but in uncontrolled area $9 / 20(45 \%), 3 / 20(15 \%)$ and $8 / 20(40 \%)$ affect adult, young and all 
Citation: Bedada H, Terefe G, Tolossa YH (2015) Current Status of Ectoparasites in Sheep and Management Practices against the Problem in Ectoparasites Controlled and Uncontrolled Areas of Arsi Zone in Oromia Region, Ethiopia. J Veterinar Sci Technol S10: 002. doi:10.4172/21577579.S10-002

Page 3 of 7

age group respectively. In controlled area 18/40 (45\%), 5/40 (12.5\%) and $17 / 40(42.5 \%)$ respondent indicated that lice affect adult, young and all. While in uncontrolled area $8 / 20(40 \%) 2 / 20(10 \%)$ and $10 / 20$ (50\%) affect adult, young and all age group respectively. Seasonality in occurrence of mange, keds and tick in controlled area were observed by $57.5 \%, 52.5 \%$ and $72.5 \%$ of the respondents respectively and also in uncontrolled area seasonality of mange, keds and tick were observed by $60 \%, 60 \%$ and $45 \%$ of respondents respectively (Figure 1). As of respondents, the season of occurrence of these diseases was reported as late rainy (cold) season for mange, dry season for keds and rainy season for tick.

Most of respondents from controlled and uncontrolled area believe that mange has effect on the sale of affected skins and more than $90 \%$ of respondents found in both controlled and uncontrolled area believe that mange has effect on the sale of live sheep. The majority of the respondents of both controlled and uncontrolled area do not believe keds, lice and ticks have effect either on the sale of the affected sheep or its skin.

Even though modern veterinary service delivery is available in their nearby only $10 \%$ in controlled area and 5\% in uncontrolled area use modern treatment to control ectoparasites None of the respondents of both controlled and uncontrolled area apply acaricides to treat the infected sheep, but acaricide spray was implemented by the government in controlled area. According to the respondents found in both controlled and uncontrolled area there were no policy which prevent the movement of animals from one area to the other even from uncontrolled area to the controlled.

According to the respondents all of the hide and skin collectors were engaged on collecting hide and skin before three years, $66.7 \%$ of controlled area and 50\% of uncontrolled area hide and skin collectors were involved in this work over five years. All respondents of hide and skin collectors of both controlled and uncontrolled area were set size of the skin, knife cut, existence of ectoparasite and putrefied skin as a parameter for purchasing. In addition to the above preconditions mechanical damage, scratch and scar were also among the parameters that all skin collectors of controlled area and $66.67 \%$ skin collectors of uncontrolled area used to collect the skin. Ectoparasites were the main factor that hide and skin collectors looking for; in both controlled as well as uncontrolled area all hide and skin collectors were considering whether the skin infested with mange and lice. In both area $33.33 \%$ of the collectors of hide and skin were looking over the existence and infestation of the skin with tick, while all of uncontrolled area skin collectors and $66.67 \%$ of the collectors of controlled area were regarding for the infestation of skin with keds.

According to response of all collectors of both controlled and uncontrolled area; tanners established size of the skin, existence of knife cut, infestation of skin with ectoparasites (if the skin is fresh), putrefied skin, mechanical damage, scratch and scar were the main parameters to receive hide and skin from collectors. All collectors of both controlled and uncontrolled area were respond that tanners were looking for the infestation of skin with mange and lice during receiving the collected skin. From the total 9 hide and skin collectors interviewed, $3 / 6(50 \%)$ and 2/3 (66.67\%) respondents from controlled and uncontrolled area respectively believe that tanners are looking for whether the skin affected by tick or not and according to $2 / 3(66.67 \%)$ collectors of uncontrolled area were also respond that tanners look for the existence of skin affected by lice. According to the response of all hide and skin collectors of controlled and uncontrolled area the value of the skin infested with ectoparasite were worth $50 \%$ less cost than the healthy skin. As the collectors brought the skin to the tanners, tanners look for either the skin affected by the ectoparasites or not. Hence, the main reason that ectoparasite infested skin was cost less than the healthy one

All the hide and skin collectors of both controlled and uncontrolled area stored the collected skin by sorting with salt. In both area $33.33 \%$ of the collectors were stored the collected skin from four to eight weeks while $66.67 \%$ of the collectors of both controlled and uncontrolled area were stored the skin for more than two months.

\section{Prevalence of ectoparasites}

Out of 646 sheep examined from the controlled districts 371 (57.43\%) were infested with one or more ectoparasites. The major ectoparasites identified on sheep from controlled area were $49.85 \%$ lice, tick $9.7 \%$, sheep keds $7.4 \%$ and $12.5 \%$ mixed infestation. In

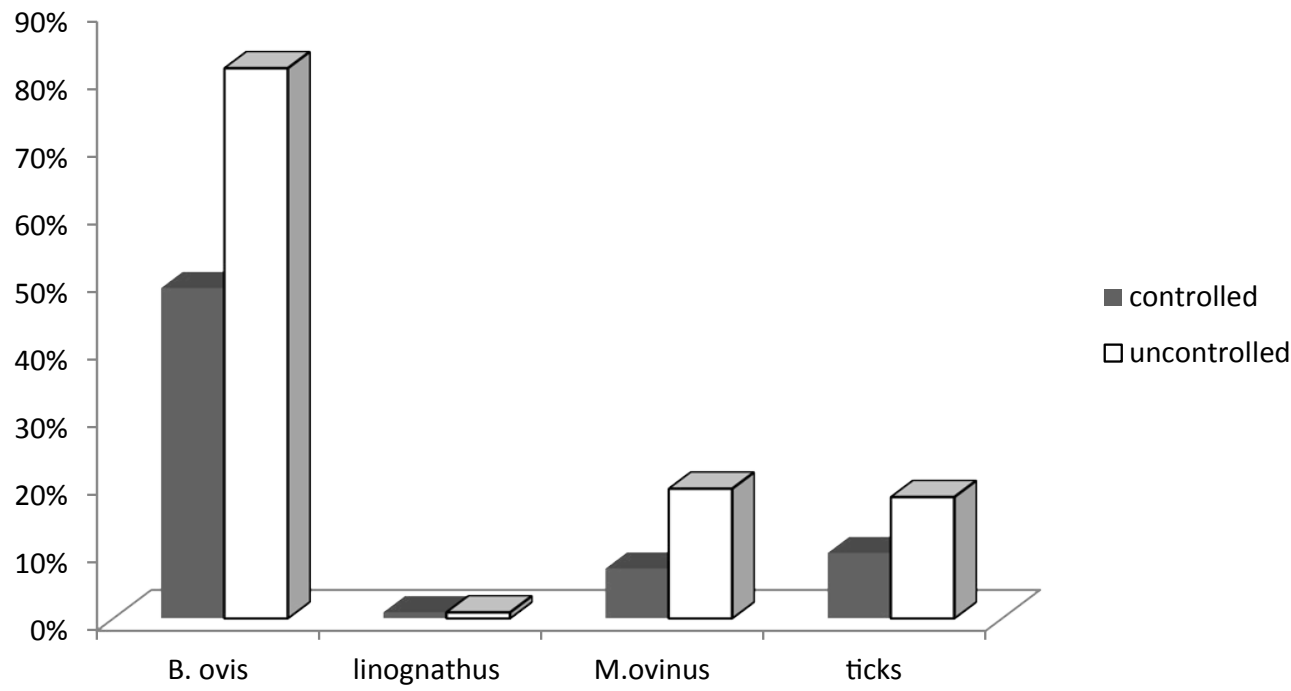

Figure 1: Overall prevalence of ectoparasites in controlled and uncontrolled area. 
Citation: Bedada H, Terefe G, Tolossa YH (2015) Current Status of Ectoparasites in Sheep and Management Practices against the Problem in Ectoparasites Controlled and Uncontrolled Areas of Arsi Zone in Oromia Region, Ethiopia. J Veterinar Sci Technol S10: 002. doi:10.4172/21577579.S10-002

Page 4 of 7

uncontrolled area from 323 sheep examined for ectoparasite infestation 285 (88.24\%) were infested with one or more ectoparasites (Table 1). Ectoparasites identified from sheep of uncontrolled district were lice $82.35 \%$, sheep keds $19.2 \%, 17.97 \%$ tick and $32.19 \%$ mixed infestation. Lice species recovered from controlled and uncontrolled districts were $B$. ovis $48.9 \%$ in controlled area and $81.4 \%$ from uncontrolled area; Linognathus spp $0.93 \%$ from controlled area and $0.9 \%$ from uncontrolled area. The tick species identified on sheep from controlled area were $2.32 \%$ R. B. decoloratus, $1.46 \%$ A. variegatum, $1.08 \%$ A. gemma, $4.59 \% R$ evertsi evertsi, and $0.31 \%$ mixed infection. The tick species identified on sheep from uncontrolled area were $1.79 \%$ R. $B$. decoloratus, $2.62 \%$ A. variegatum, $9.29 \% R$. evertsi evertsi and $4.3 \%$ mixed infection.

The common sites of lice infestation on 316 sheep from controlled area were the shoulder, the neck, the flank and the rump with proportion of $63.9 \%, 62.66 \%, 56 \%$ and $77.1 \%$ respectively. The common sites of lice recovered from 263 sheep from uncontrolled area were $64.3 \%$ from shoulder, $45.6 \%$ from neck, $61.6 \%$ from flank and $61.9 \%$ from the rump. In M. ovinus infested sheep from controlled area the sites commonly parasitized were the shoulder $(81.2 \%)$, rump (66.67\%) the neck $(34.4 \%)$, and the flank (6.25\%) in order of importance. The sites of $M$. ovinus recovered from sheep of uncontrolled area were shoulder (83.8\%), the (35.5\%) neck (30.65\%), the rump and (1.6\%) the flan. The major tick attachment sites on the sheep of controlled area were head/ ear $(26.9 \%)$, the tail (38\%) the feet (19\%) and inter digital space $(61.9 \%)$ whereas the remaining were found to attach at other sites of the body while the major attachment site of tick recovered from uncontrolled area were head/ear (53.45\%), the tail (44.8\%) the feet (29.3\%) and inter digital space $(62 \%)$ whereas the remaining were found to attach at other sites of the body.

Lice counted on a sheep of controlled area were range from 0 minimum and 257 maximum while in uncontrolled area the count of lice were 0 minimum and 489 maximum were registered. The minimum count for keds in controlled area were 0 and maximum 64, but in sheep of uncontrolled area 0 minimum and 107 maximum were registered. The count of tick in controlled area 0 minimum and 12 maximum were registered, in uncontrolled area 0 minimum and 17 maximum were registered. Most frequently lice, ked and tick number lies in the range of 51-100, 11-20 and 6-10 counts in controlled area respectively while in uncontrolled area most frequently lice, keds and tick number lies in the range of 101-200, 21-50 and 6-10 respectively.

\section{Prevalence of ectoparasites by control status}

The overall prevalence of ectoparasite was significantly higher in uncontrolled area (88.24\%) than in controlled area $(57.43 \%)$ $(\mathrm{OR}=5.644, \mathrm{P}=0.000)$ (Table 2). Control specific prevalence of ectoparasites identified on sheep was shown in Figure 1. The prevalence of $M$. ovinus among the controlled and uncontrolled area showed significant difference $(\mathrm{OR}=3.836, \mathrm{p}=0.000)$. A similar logistic regression analysis performed on lice prevalence among the controlled and uncontrolled area revealed significant difference between two areas $(\mathrm{OR}=7.061, \mathrm{p}=0.000)$. A significant difference in prevalence of ticks $(\mathrm{OR}=2.074, \mathrm{p}=0.000)$ were found between controlled and uncontrolled area (Figure 1).

\section{Prevalence of ectoparasites by sex}

The overall prevalence of ectoparasite in female and male was $88.68 \%$ and $88.23 \%$ and $63.1 \%$ and $44.4 \%$ in uncontrolled and controlled area respectively (Table 3 ). The prevalence of ectoparasites was significantly
$(\mathrm{OR}=0.455, \mathrm{p}=0.000)$ higher in the female animals than male animals in the controlled area. Statistically significant difference in prevalence of lice $(\mathrm{OR}=1.129, \mathrm{p}=0.000)$ infestation was observed between female and male sheep of controlled area. Also statistically significant difference in prevalence of tick was recorded between male and female sheep of uncontrolled area $(\mathrm{OR}=1.861, \mathrm{p}=0.035)$.

\section{Prevalence of ectoparasites by age}

The overall prevalence of ectoparasite in young and adult sheep of controlled and uncontrolled area was $56.9 \%$ and $57.8 \%$ and $88.2 \%$ and $88.3 \%$ respectively (Table 4 ). Statistically significant difference was never recorded $(\mathrm{p}>0.05)$ in the overall prevalence of lice, tick and $M$.

\section{Prevalence of ectoparasites by body condition}

The overall prevalence of ectoparasites in good and poor body condition sheep were $58.3 \%$ and $56.7 \%$ in controlled area, and $90.8 \%$ and $86.2 \%$ in uncontrolled area respectively (Table 5). The logistic regression results showed statistically significance difference in prevalence of tick infestations $(\mathrm{OR}=0.478, \mathrm{p}=0.015)$ between sheep with poor and good body condition in uncontrolled area.

\section{Prevalence of ectoparasites by hair size/type}

The overall prevalence of ectoparasites in hairy and wooly sheep of controlled area was $55.3 \%$ and $59.6 \%$ respectively while in uncontrolled area the overall prevalence was $78.9 \%$ hairy sheep and $48.7 \%$ in woolly (Table 6). Statistically significant difference in prevalence of $M$. ovinus between hairy and wooly sheep was observed in both controlled area $(\mathrm{OR}=0.081, \mathrm{p}=0.000)$ and uncontrolled area $(\mathrm{OR}=0.017, \mathrm{p}=0.000)$ Statistically significant difference in prevalence of lice infestation between hairy and wooly sheep was also observed in controlled area $(\mathrm{OR}=0.715, \mathrm{p}=0.036)$.

\begin{tabular}{|c|c|c|c|}
\hline Ectoparasite & $\begin{array}{c}\text { Controlled } \\
\text { area(n=646) }\end{array}$ & $\begin{array}{c}\text { Uncontrolled area } \\
(\mathbf{n = 3 2 3 )}\end{array}$ & P-value \\
\hline Lice & $49.85(322)$ & $82.35(266)$ & \\
\hline B. ovis & $48.3(312)$ & $81.4(263)$ & 0.000 \\
\hline Linognathus spp & $0.93(6)$ & $0.9(3)$ & \\
\hline Tick & $9.7(63)$ & $17.97(58)$ & 0.000 \\
\hline R(B). decoloratus & $2.32(15)$ & $1.79(6)$ & \\
\hline A. variegatum & $1.46(9)$ & $2.62(8)$ & \\
\hline A. gemma & $1.08(7)$ & - & \\
\hline R. evertsi evertsi & $4.59(30)$ & $9.29(30)$ & \\
\hline Mixed infection & $0.31(2)$ & $4.3(14)$ & 0.000 \\
\hline M. ovinus & $7.4(48)$ & $19.2(62)$ & 0.000 \\
\hline Overall & $57.43(371)$ & $88.24(285)$ & \\
\hline
\end{tabular}

Table 1: Prevalence of ectoparasites in controlled and uncontrolled areas

\begin{tabular}{|c|c|c|c|c|c|c|}
\hline \multirow{2}{*}{ Ectoparasites } & \multirow{2}{*}{$\begin{array}{l}\text { Control status } \\
\text { (risk factor) }\end{array}$} & \multirow{2}{*}{ SE } & \multirow{2}{*}{$p$-value } & \multirow{2}{*}{ OR } & \multicolumn{2}{|c|}{$95 \% \mathrm{Cl}$ for OR } \\
\hline & & & & & Lower & upper \\
\hline \multirow{2}{*}{ Overall } & Controlled ${ }^{a}$ & 1 & 1 & 1 & 1 & 1 \\
\hline & Uncontrolled & 0.191 & 0.000 & 5.644 & 3.881 & 8.207 \\
\hline \multirow{2}{*}{ Lice } & Controlled $^{a}$ & 1 & 1 & 1 & 1 & 1 \\
\hline & Uncontrolled & 0.196 & 0.000 & 7.061 & 4.812 & 10.360 \\
\hline \multirow{2}{*}{ Keds } & Controlled $^{a}$ & 1 & 1 & 1 & 1 & 1 \\
\hline & Uncontrolled & 0.223 & 0.000 & 3.836 & 2.478 & 5.939 \\
\hline \multirow{2}{*}{ Tick } & Controlled ${ }^{a}$ & 1 & 1 & 1 & 1 & 1 \\
\hline & Uncontrolled & 0.192 & 0.000 & 2.074 & 1.424 & 3.021 \\
\hline
\end{tabular}

SE standard error, OR odds ratio, a Reference category

Table 2: Summary of binary logistic regression of ectoparasites according to control status. 
Citation: Bedada H, Terefe G, Tolossa YH (2015) Current Status of Ectoparasites in Sheep and Management Practices against the Problem in Ectoparasites Controlled and Uncontrolled Areas of Arsi Zone in Oromia Region, Ethiopia. J Veterinar Sci Technol S10: 002. doi:10.4172/21577579.S10-002

Page 5 of 7

\begin{tabular}{|c|c|c|c|c|}
\hline \multirow{2}{*}{$\begin{array}{c}\text { Ectoparasite } \\
\text { type }\end{array}$} & \multicolumn{2}{|c|}{ Controlled area } & \multicolumn{2}{c|}{ Uncontrolled area } \\
\cline { 2 - 5 } Male(n=196) & Female(n=450) & Male(n=102) & Female(n=221) \\
\hline B. ovis & $39.3(74)$ & $54.4(238)$ & $83.3(85)$ & $81(178)$ \\
\hline Linognathus spp & $1.02(2)$ & $0.88(4)$ & $1.9(2)$ & $0.5(1)$ \\
\hline M. ovinus & $9.7(19)$ & $6.4(29)$ & $17.6(18)$ & $19.9(44)$ \\
\hline Ticks infestation & $8.2(16)$ & $10.4(47)$ & $23.5(24)$ & $15.4(34)$ \\
\hline Overall & $44.4(87)$ & $63.1(284)$ & $88.23(90)$ & $88.68(195)$ \\
\hline
\end{tabular}

Table 3: Prevalence of ectoparasites in controlled and uncontrolled area by sex.

\begin{tabular}{|c|c|c|c|c|}
\multirow{2}{*}{ Ectoparasite } & \multicolumn{2}{|c|}{ Controlled area } & \multicolumn{2}{c|}{ Uncontrolled area } \\
\cline { 2 - 5 } & Young(n=267) & adult(n=379) & Young(n=127) & adult(n=196) \\
\hline B. ovis & $47.6(127)$ & $48.8(185)$ & $83.3(102)$ & $82.2(161)$ \\
\hline $\begin{array}{c}\text { Linognathus } \\
\text { spp }\end{array}$ & $1.5(4)$ & $0.5(2)$ & $2.4(3)$ & - \\
\hline Tick & $10.1(27)$ & $9.5(36)$ & $14.9(19)$ & $19.9(39)$ \\
\hline M. ovinus & $7.5(20)$ & $7.4(28)$ & $16.5(21)$ & $20.9(41)$ \\
\hline Overall & $56.9(152)$ & $57.8(219)$ & $88.2(112)$ & $88.3(173)$ \\
\hline
\end{tabular}

Table 4: Prevalence of ectoparasites in controlled and uncontrolled area by age.

\begin{tabular}{|c|c|c|c|c|}
\hline \multirow{2}{*}{ Ectoparasite } & \multicolumn{2}{|c|}{ Controlled } & \multicolumn{2}{c|}{ Uncontrolled() } \\
\cline { 2 - 5 } & Poor(363) & Good(283) & Poor(181) & Good(465) \\
\hline B. ovis & $47.4(172)$ & $58.3(165)$ & $79(143)$ & $84.5(120)$ \\
\hline Linognathus spp & $1.1(4)$ & $49.5(140)$ & $1.1(2)$ & $0.7(1)$ \\
\hline M. ovinus & $7.7(28)$ & $0.7(2)$ & $19.3(35)$ & $19(27)$ \\
\hline Ticks & $9.1(33)$ & $10.6(30)$ & $22.6(41)$ & $11.9(17)$ \\
\hline Overall & $56.7(206)$ & $58.3(165)$ & $86.2(1156)$ & $90.8(129)$ \\
\hline
\end{tabular}

Table 5: Ectoparasites prevalence in controlled and uncontrolled area by body condition.

\begin{tabular}{|c|c|c|c|c|}
\hline Ectoparasite & \multicolumn{2}{|c|}{ Controlled area } & \multicolumn{2}{c|}{ Uncontrolled area } \\
\hline & Hairy(n=322) & Woolly(n=324) & Hairy(n=171) & Woolly(n=152) \\
\hline B. ovis & $44.7(144)$ & $51.8(168)$ & $78.9(135)$ & $84.2(128)$ \\
\hline Linognathus spp & $0.93(3)$ & $0.92(3)$ & $1.1(2)$ & $0.7(1)$ \\
\hline M. ovinus & - & $14.8(48)$ & - & $40.8(62)$ \\
\hline Ticks & $11.2(36)$ & $8.3(27)$ & $15.2(26)$ & $21.1(32)$ \\
\hline overall & $55.3(178)$ & $59.6(193)$ & $78.9(148)$ & $48.7(137)$ \\
\hline
\end{tabular}

Table 6: prevalence of ectoparasites in controlled and uncontrolled area by hair type.

\section{Prevalence of ectoparasites by management}

The overall prevalence of ectoparasites in separately reared sheep and sheep reared with other animals in controlled area and uncontrolled area was $56.7 \%$ and $57.6 \%$, and $88.9 \%$ and $88.1 \%$ respectively (Table $7)$. However, significant variations $(\mathrm{p}>0.05)$ were never observed in the prevalence of B. ovis, Linognathus, M. ovinus and tick infestation between sheep reared separately and those reared with other animal in both controlled and uncontrolled area.

\section{Discussion}

Results of this study revealed an overall prevalence of ectoparasites $57.43 \%$ in controlled area and $88.24 \%$ in uncontrolled area. This finding is most probably attributable to several important factors including management problems, conducive environment, malnutrition and poor husbandry systems, poor awareness of farmers; inadequate veterinary services [14] and in efficiency of the ongoing control campaign against ectoparasites the study districts and absence animals movement policy from one place to the other as well as lack of knowledge by farmers about quarantine of newly introduced animals that could easily get access to the ectoparasites controlled area [3]. Other factors which might be contributed for high prevalence of ectoparasite in controlled area were the method of acaricides application (spray). During spray the formulated liquid acaricide might not reach at the base of the skin and all part might not cover with acaricides. As a fact that ectoparasite are most often introduced to herds by introducing newly arriving infested animals [15]. However the overall prevalence was significantly lower in controlled area than uncontrolled area. Sheep of uncontrolled area were 5.644 times at risk for ectoparasite infestation than sheep found in controlled. The findings of the current study in ectoparasite controlled area are in agreement with the previous reports from different parts of the country [10,16-19]. The findings of uncontrolled area is comparable with the previous reports from different parts of Ethiopia [8] who reported high prevalence and great importance of ectoparasites in small ruminants.

The overall prevalence of ectoparasite $(\mathrm{p}=0.000)$ and tick infestation $(\mathrm{p}=0.035)$ in female sheep of controlled area was significantly higher than male sheep. Female sheep were 0.455 times and 1.861 times at risk for overall ectoparasite infestation and tick infestation than male respectively. This finding probably attributable to several important factors such as ewes are kept by the farmer for long period of time for breeding purpose but male sheep are sold before two years of age, hence the treated ewes might be exposed to re-infestation as they stay on farm for long time. In addition during breeding season ewes are in close contact with many rams for long time which might increase the risk of getting ectoparasites from infested ram. Clinically affected and carrier animals are the source of infection [20]. Ewes might also acquire ectoparasites during nursing from infested lamb which was born after control campaign. Also some species of ectoparasite such as tick spend more time off the host and can exist for a very long period of time without feeding due to no more application of environmental treatment females those kept for breeding after control campaign might get infested.

Lice were the most prevalent ectoparasites in both controlled and uncontrolled areas with a prevalence of $49.85 \%$ and $82.35 \%$ respectively. The effects of climate change and other factor such as changes in animal management and husbandry systems, usage of acaricides and increase in animal trafficking or movements may also contribute to the changes in the prevalence, or emergence, of lice infestation in certain localities [16]. Hence, prevalence of lice infestation was significantly higher in uncontrolled area than controlled area $(\mathrm{p}=0.000)$ and sheep found in uncontrolled area were 7.061 times at risk for lice infestation than sheep of controlled area. The prevalence of lice recorded in the controlled area is higher than the findings of Mulugeta et al. [17] from east Wollega, in west of Ethiopia (5.26\%); 3.2\% from Bahir Dar northwest Ethiopia

\begin{tabular}{|c|c|c|c|}
\hline \multirow{2}{*}{ Ectoparasite } & \multicolumn{2}{|c|}{ Controlled area } & \multicolumn{2}{c|}{ Uncontrolled area } \\
\cline { 2 - 4 } & Separately(n=120) & Mixed(n=526) & Separately(n=63) \\
\hline B. ovis & $43.3(52)$ & $49.4(260)$ & $80.9(51)$ \\
\hline Linognathus spp & $1.7(2)$ & $0.7(4)$ & - \\
\hline M. ovinus & $5.8(7)$ & $7.8(41)$ & $1.2(3)$ \\
\hline Ticks & $11.7(14)$ & $9.3(49)$ & $17.7(46)$ \\
\hline Overall & $56.7(68)$ & $57.6(303)$ & $25.4(16)$ \\
\hline
\end{tabular}

Table 7: Prevalence of ectoparasites in controlled and uncontrolled area by management. 
Citation: Bedada H, Terefe G, Tolossa YH (2015) Current Status of Ectoparasites in Sheep and Management Practices against the Problem in Ectoparasites Controlled and Uncontrolled Areas of Arsi Zone in Oromia Region, Ethiopia. J Veterinar Sci Technol S10: 002. doi:10.4172/21577579.S10-002

Page 6 of 7

[21] and $15.3 \%$ from southeast part of Tigray region north Ethiopia [18]. But this prevalence is lower than the recorded in the north part of Amhara region $57.2 \%$ y [22]. Such differences in prevalence might arise from season during which the study was conducted, variations in management, breed and health care of sheep in the study areas, and the sensitivity of the diagnostic method used. Lice infestation may reflect some other underlying problems such as malnutrition and chronic diseases. The possible reasons for such high prevalence of lice in the study area include management problems, poor feeding, and inadequate veterinary services.

The prevalence of lice was significantly higher in woolly sheep of controlled area than hairy sheep and wooly sheep of controlled area were 0.715 times at risk for lice infestation. Such difference might arise due to the fact that the skin's microclimate is a significant factor in determining the size of the louse population on the sheep. Thinness of hair coats in coupled with high surface temperatures and increased exposure to sunlight is not favorable for survival of lice [23]. Sheep have heavy fleece provide a habitat which is readily colonized by lice and lice is susceptible to high temperature [14]. B. ovis was the most common louse that infesting sheep of both controlled and uncontrolled area. The prevalence of $B$. ovis recorded in uncontrolled area is comparable with results by Jemere [24] in central Ethiopia which was $83.23 \%$.

M. ovinus was the second and third most important ectoparasite observed on sheep of uncontrolled area and sheep of controlled area accounting for $19.2 \%$ and $7.4 \%$ overall prevalence respectively. The overall prevalence of sheep keds was significantly higher in uncontrolled area $(\mathrm{p}=0.000)$. Sheep of uncontrolled area were 3.836 times at risk for M. ovinus infestation than controlled sheep. According to Radostitis [25] in the hot, humid tropics the parasite is restricted to cooler highlands and infestations may be lost when sheep are moved to hot dry areas suggesting that temperature may play an important role in the dynamics of the keds. The finding of higher prevalence $M$. ovinus on wooly sheep of both controlled and uncontrolled are $(7.4 \%)$ and (19.2) respectively while its total absence from hairy sheep of both area is suggestive of the fact that wooly breeds are susceptible to ked [14]. Hairy sheep of controlled area and uncontrolled area were 0.081 times and 0.715 times at risk for M. ovinus infestation respectively.

The prevalence of $M$. ovinus recorded in the controlled area is comparable with work made in other parts of the country $3.47 \%$ by Mulugeta et al. [17] from east Wollega in western Ethiopia. Similarly the findings of $M$. ovinus in sheep of uncontrolled area is in agreement with previous works conducted in different part of the country by Yacob et al. [18]; 19.1\% from southeast part of Tigray region north Ethiopia, [26], 16.4\% from central Oromiya and $20.1 \%$ of sheep keds in Gondar from northwest Ethiopia by Kumsa et al. [22].

Tick infestations with an overall prevalence of $9.7 \%$ from controlled area and $17.97 \%$ from uncontrolled areas. In the current study an overall prevalence of tick in both controlled and uncontrolled area were less than most studies accompanied in the country this might be due to higher temperatures and relative humidity and prolonged sunlight favors the survival and reproduction of ticks, as has been suggested by Kumsa et al. Pegram et al. [26,27]. The overall prevalence of tick in uncontrolled area was significantly higher than controlled area $(\mathrm{p}=0.000)$. This finding is in agreement with the previous observations reported by Yacob et al. [18]; 16\% in Tigray; [22]; 21.2\%, in Gondar; by Asnake Fekadu et al. [9], 18.8\%; from southern part of Ethiopia; and $19.2 \%$ reported from Ambo by Tadese et al. [28]. The prevalence of tick infestations in poor sheep of uncontrolled area was significantly $(\mathrm{p}=0.015)$ higher than sheep with good body condition and sheep with poor body condition score were 0.478 times higher at risk of infestation by ticks than those sheep with good condition. This finding coincides with the previous reports of Yacob et al, Tewodros, Tefera et al. $[18,22,29]$.

In conclusion, the most important ectoparasites identified in this study were lice, sheep keds and tick. Lice were the most abundant ectoparasite in both area followed by sheep keds and tick in uncontrolled area and tick and sheep ked in controlled area. In view of the findings of the present study it is possible to conclude that even though control campaign were implemented several species of ticks, lice, and $M$. ovinus represent still common health and productivity problems of sheep in both controlled and uncontrolled areas in Arsi zone. Age and management were not found as a risk factor of all ectoparasite infestation in the current study. However, sex, body condition and hair type were important factors for different ectoparasite infestation in current study. The problem is still very serious and there are still animals suffering from ectoparasitism in ectoparasites control campaign regions, threatening the national economy, sheep and goat population and tanning industries. Lack of awareness creation and absence of control on animal movement and poor quarantine policy might have resulted in ineffectiveness of the control campaigns. This threat of ectoparasites on overall sheep productivity and tanning industry in Ethiopia warrants urgent strategic control intervention based on peculiar characteristic of each agro-ecology.

\section{References}

1. CSA (2012) Federal Democratic Republic of Ethiopia, Central Statistical Agency Agricultural Sample Survey. Report on livestock and livestock characteristics, Addis Ababa.

2. Degume W (2002) Production and Marketing Problem of AMALGMA. In Parenti A (ed) Proceedings of Challenges and Solutions for Ethiopian Leather Industry. UNIDO, Addis Ababa.

3. Tolossa YH (2014) Ectoparasitism: Threat to Ethiopian Small Ruminan Population and Tanning Industry. Jvmah 6: 25-33.

4. ESGPIP (2010) Control of external parasite of sheep and goat, Ethiopian Society of Animal Production (ESAP). Technical bulletin 41: 2-11.

5. Yacob Hailu Tolossa (2013) Skin defects in small ruminants and their nature and economic importance: The case of Ethiopia. Global Veterinaria 5: 107-112.

6. Kassa B (2005) Pre-slaughter defects of hides/skin and intervention options in east Africa: Harnessing the leather industry to benefit the poor. Addis Ababa, Ethiopia. pp. 71-84.

7. Chanie M, Negash T, Sirak A (2010) Ectoparasites are the major causes of various types of skin lesions in small ruminants in Ethiopia. Trop Anim Health Prod 42: 1103-1109.

8. Amare S, Asfaw Y, Hailu Y (2013) ectoparasites of sheep and goat north west Amhara regional state Ethiopia. Ethiopian Veterinary Journal 17: 55-62.

9. Asnake Fekadu, Yacob Hailu Tolossa, Hagos Ashenafi (2013) Ectoparasites of small ruminants in three ago-ecological Districts of Southern Ethiopia. Ajbas 5: 47-54.

10. Hailu W (2010) Study on prevalence of major ectoparasites of sheep and the major risk factors in Arsi zone of Oromia region and evaluate the in vitro and in vivo acaricidal efficacy of seven medicinal plants against lice in naturally infested sheep. MSc thesis, Addis Ababa University, Dere-Zeit, Ethiopia.

11. Thrusfield M (2007) VeterinaryVepidemiology (3rd edn) UK Blackwell Science Ltd. pp. 261

12. Gatenby MR (1991) Sheep. In: Coste R, Smith JA (eds) The Tropical Agriculturalist. London: Macmillan and CTA (Wageningen) pp. 6-11.

13. Walker AR, Bouattour A, Camicas JL, Estrada-Pena A, Horak IG, et al. (2003) Ticks of domestic animals in Africa: A guide to identification of species, ICTTD-2. Bioscience Reports, London.

14. Wall R, Shearer D (2001) Veterinary ectoparasites biology, pathology and control (2nd Edn). 
Citation: Bedada H, Terefe G, Tolossa YH (2015) Current Status of Ectoparasites in Sheep and Management Practices against the Problem in Ectoparasites Controlled and Uncontrolled Areas of Arsi Zone in Oromia Region, Ethiopia. J Veterinar Sci Technol S10: 002. doi:10.4172/21577579.S10-002

15. Kufman PE, Koehler PG, Butler JF (2012) External Parasites of Sheep and Goats. University of Florida. IFSA extension. pp. 168-200.

16. Shibeshi B, Bogale B, Chanie M (2013) Ectoparasites of Small Ruminants in Guto-Gidda District, East Wollega, Western Ethiopia. Acta Parasitologica Globalis 4: 86-91.

17. Mulugeta $\mathrm{Y}$, Yacob HT, Ashenafi H (2010) Ectoparasites of small ruminants in three selected agro-ecological sites of Tigray Region, Ethiopia. Trop Anim Health Prod 42: 1219-1224.

18. Yacob HT, Yalew AT, Dink AA (2008) Ectoparasites prevalence in sheep and in goats in and around Wolaita soddo, Southern Ethiopia. part I, Revue Méd Vét.159: 450-454.

19. Yacob HT, Netsanet B, Dinka A (2008) Prevalence of major skin disease in cattle, sheep and goats at Adama veterinary clinic, Oromia regional state, Ethiopia, part II. Revue Med Vet 8: 455-461.

20. Mekonnen S, Pegram RG, Gebre S, Mekonnen A, Jobre Y, et al. (2007) A synthesis of ixodid (Acari: Ixodidae) and argasid (Acari: Argasidae) ticks in Ethiopian and their possible roles in disease transmission. Ethiopian Veterinary Journal 11: 1-17.

21. Dawit T, Mulugeta A, Tilaye D, Mengistie T (2012) Ectoparasites of small ruminants presented at Bahir Dar Veterinary Clinic, Northwest Ethiopia. Ajar 7: 4669-4674.

22. Tewodros F, Fasil W, Mersha C, Malede B (2012) Prevalence of Ectoparasites on Small Ruminants in and Around Gondar Town. American-Eurasian J Sci Res 7: 106-111.
23. Changbunjong T, Buddhirongawatr R, Suwanpakdee S, Siengsanan J, Yongyuttawichai $P$, et al. (2009) A survey of ectoparasitic arthropods on domestic animals in Tak Province, Thailand. Southeast Asian J Trop Med Public Health 40: 435-442.

24. Jemere B, Martha T, Rahmeto A (2011) External Parasite Infestations in Smal Ruminants in Wolmera District of Oromiya Region, Central Ethiopia. JAVA 10: 518-523.

25. Radostitis OM, Blood DC, Gray CC (1994) Veterinary Medicine: A textbook of the disease of cattle, sheep, pigs, goats and horses (8th edn) BailliereTindall UK pp. 304-309.

26. Kumsa B, Beyecha K, Geloye M (2012) Ectoparasites of sheep in three agroecological zones in central Oromia, Ethiopia. Onderstepoort J Vet Res 79: E1-

27. Pegram RG, Hoogstral H, Wassef HY (1981) Ticks (Ixodidae) of Ethiopia: Distribution, ecology and host relationship of tick species affecting livestock. Bulletin of Entomological Research 71: 339-359.

28. Tadese B, Nuraddis I, Mandefro D (2013) Prevalence of ovine ectoparasites in and around Ambo town, in Ethiopia. Middle-east journal of scientific research 16: $62-67$

29. Tefera S, Abebe W (2006a) A study on ectoparasites of sheep and Goats in Eastern part of Amhara region, Northeast Ethiopia. JSRR 12: 21-25. 